\title{
Peri-insular hemispherotomy in paediatric epilepsy
}

\author{
Jean-Guy Villemure $\cdot$ Roy Thomas Daniel
}

Received: 28 February 2006 / Published online: 29 June 2006

(C) Springer-Verlag 2006

\begin{abstract}
Objects Outline the indications, investigation, surgical technique, pitfalls, complications and benefits of periinsular hemispherotomy (PIH) in the surgical treatment of paediatric epilepsy.

Materials and methods This report is based on a consecutive series of 43 children who underwent PIH. Sixty percent were males; there were slightly more left-sided surgeries. Median interval between seizure onset and surgery was 5 years. In more than half the cases, the anatomical substrate was congenital. There were few complications: one death, one hydrocephalus and two anatomically remote haemorrhages. Ninety percent of the patients have remained in Engel's class I epilepsy outcome. Conclusions There are clear indications for hemispherectomy in children. In some instances of incomplete deficit, timing of surgery remains a major concern. The less invasive approach to eliminate the influence of the diseased hemisphere, in our opinion, is with disconnective techniques of hemispherectomy, and among the latter, peri-insular hemispherotomy provides, in our opinion, the best complications-benefits ratio.
\end{abstract}

J.-G. Villemure $(\square)$

Neurosurgery Service,

Centre Hospitalier Universitaire Vaudois,

Rue du Bugnon 46,

1011 Lausanne, Switzerland

e-mail: jean-guy.villemure@chuv.ch

R. T. Daniel

Neurosurgery Service,

Christian Medical College,

Vellore, India
Keywords Peir-insular · Hemispherotomy · Epilepsy

surgery $\cdot$ Hemispherectomy

\section{Introduction}

Functional hemispherectomy (FH) was introduced in the 1970s as a surgical method aiming at achieving the same seizure outcome obtained with anatomical hemispherectomy $(\mathrm{AH})$, while avoiding the known potential complications of the latter, namely superficial cerebral hemosiderosis $[19,27,30,31,54]$. FH consists in an anatomical subtotal removal of the hemisphere but with complete disconnection. It requires removal of the central region, including the parasagittal tissue, temporal lobectomy, complete callosotomy, frontal and parieto-occipital lobotomies. The disconnected frontal and parieto-occipital lobes are left in place, vascularized. The insular cortex is removed $[32,38]$.

The experience acquired with FH has allowed, on one side, to confirm the expected benefits, i.e. seizure outcome comparable to $\mathrm{AH}$, and on the other side, has led technically to smaller brain removal to achieve hemispheric disconnection [49]. Peri-insular hemispherotomy (PIH) results from the conceptual and technical evolution of $\mathrm{FH}$ and represents the latest stage in its development [24, 25, 44, 46].

While the first series of hemispherectomy carried out by Dandy [10] was for the treatment of gliomas, the indication for this surgical method rapidly shifted toward the treatment of refractory hemispheric epilepsy. The first reports on the use of hemispherectomy for epilepsy were those of McKenzie in 1938 [26] concerning a child with infantile hemiplegia, and later on, of Krynauw in 1950 concerning a series of 12 children with infantile hemiplegia [21]. We 
Table 1 Summary of patients data

report our experience with peri-insular hemispherotomy in a consecutive series of 43 children.

\section{Materials and methods}

Disconnective hemispherectomy, i.e. FH and PIH, were carried out in 84 patients for the treatment of refractory hemispheric epilepsy (Fig. 23). There were 60 children (71\%) and 24 adults. Of the paediatric population, 43 underwent $\mathrm{PIH}(71 \%)$ and 17 underwent $\mathrm{FH}$.

In this report, we describe our experience with periinsular hemispherotomy in refractory paediatric hemispheric epilepsy. We discuss the indications, the anatomical substrates, technical steps, pitfalls, benefits and complications in a consecutive series of 43 paediatric patients (Table 1).

There were 25 males and 18 females. Age at surgery ranged from 1 to 15 years (mean: 8 , median: 7.5). There were 19 surgeries on the right and 24 on the left. The interval between seizure onset and surgery varied from 1 to 12 years (mean: 5, median: 4.5). The anatomical substrates responsible for seizures were: infantile hemiplegia in 17 , chronic encephalitis in 13, trauma in one, hemimegalencephaly in three, non-hypertrophic migrational disorder in four, vascular insult in two, infection in two and anoxia in one (Table 2).

Table 2 Anatomical substrate in 43 cases of PIH

\begin{tabular}{lr}
\hline IHSS & 17 \\
Rasmussen's & 13 \\
Trauma & 1 \\
Hemimegalencephaly & 3 \\
Non-hypertrophic & \\
Migrational disorder & 4 \\
vascular & 2 \\
Infection & 2 \\
Anoxia & 1 \\
\hline
\end{tabular}

\section{Indications}

The indications to hemispherectomy concern a restricted population of epileptic patients who suffer from pharmacoresistant seizures. The brain insult has to be unilateral and widespread throughout the hemisphere. The anatomical substrates in such conditions are relatively already well identified and classified as hemispheric syndrome "remediable by surgery" [15]. The hemispheric disease has, in most instances, already created a "clinical hemispheric syndrome" characterized by hemiplegia and hemianopsia. The surgical decision to proceed to hemispherectomy is based on the critical evaluation of the following six parameters: seizures, neurological status, aetiologies, electroencephalography, imaging, neuropsychology [40].

\section{Seizures}

$\mathrm{PIH}$ is indicated for the treatment of refractory hemispheric epilepsy. The indication is the same, independent of the surgical method of hemispherectomy utilized. The predominant seizure pattern is focal motor, but often, patients suffer many seizure patterns, i.e. focal motor, partial complex, generalized, etc. The seizures have been documented to be pharmacoresistant, i.e. without successful control despite numerous anticonvulsants. Seizures have a frequency of a few per day to thousands per year. The seizures have a dramatic impact on the patient's psychosocial development; frequentation of normal school is exceptional, learning disabilities is the rule. The seizure frequency and/or severity may be such that regression on acquired development is noticed; this may be characterized by loss of speech abilities and aggravation of concentration or memory faculties. Abnormal behaviour, mainly hyperactivity and aggressiveness may be major elements of the clinical picture [21, 22]. Whether these represent seizure manifestations or the result of an epileptic encephalopathy are possibilities [29].

Neurological examination

Depending on the pathological substrate responsible for the seizures, the hemispheric syndrome may be complete or incomplete and either stable or progressive. Classically, the patient harbours a complete and stable hemispheric syndrome characterized by a hemiplegia and a hemianopsia. In certain conditions such as Rasmussen's chronic encephalitis or extensive Sturge-Weber at an early stage, there may be incapacitating seizures and minimal, if any, objective neurological dysfunction. In these conditions, which are on one hand progressive and on the other hand responsible for severe seizure disorder before maximal deficits, the decision to proceed to $\mathrm{PIH}$, in these instances, is based on 
the severity of the seizures, the rapidity of evolution of the underlying condition and the lack of alternative medical treatments. Surgery, when carried out before maximal deficit, will definitively aggravate the neurological status. Even though this is to be avoided when possible, PIH may be necessary in these dynamic, naturally progressive conditions, which will lead to severe hemispheric deficit with time. This management issue is a matter of experience and judgment and requires from the parents, as well, a good comprehension of the underlying disease [39, 51].

When assessing the motor function preoperatively to determine its postoperative outcome, we have found that the motor deficit is usually not made worse when preoperatively, patients are unable to perform finger opposition to the thumb, even if they are able to open and close the hand. This is particularly observed in cases of early pathology, such as infantile hemiplegia, where the lesion might have preceded the final cortical organization and allowed some plasticity mechanism to develop. The same interpretation is given to the inability to perform repeated foot tapping. Repeated alternating movement of foot taping and finger opposition to the thumb or individual finger movements depend on cortical function. The presence of gross voluntary movement, such as major joint movements, walking, gross movement of the hand, do not require cortical participation and results, in part, from subcortical structures or ipsilateral motor participation through sprouting.

We have found in six cases who preoperatively demonstrated preservation of their visual field on formal testing that the loss of visual field after hemispherectomy did not have any clinical impact. We suspect that the preserved field on formal testing in a severely damaged hemisphere is not necessarily useful in daily activities. We consider that the aggravation of visual field by hemispherectomy, in someone who otherwise meet the other criteria for surgery, is not, by itself, a contraindication to PIH [51].

The sensory examination is most often close to normal despite severe anatomical hemispheric damage. However, slight to moderate deficits can de demonstrated in most patients when testing discrimination. Specific studies on sound perception have also documented decreased precision in sound localization from the auditory field contralateral to surgery [28, 57]. Studies of visual field after hemispherectomy have demonstrated persistent vision in a narrow meridian lateral to the midline of the contralateral field, extending from 3 to $6^{\circ}$ [53].

\section{Etiologies}

The anatomical substrates responsible for seizures are either congenital or acquired. Acquired conditions are trauma, infection, Rasmussen's encephalitis; in these conditions, the brain has had a period of normal development and normal functioning for various lengths of time. In acquired conditions, one can assume that the hemispheric neurological deficit might be worse than in congenital lesion as the compensatory mechanisms, named plasticity, did not intervene as early $[3,18,55]$. Congenital anatomical substrates consist in prenatal vascular insult resulting from carotid or middle cerebral artery occlusion characteristic of the infantile hemiplegia, and extensive Sturge-Weber, hemimegalencephaly and non-hypertrophic diffuse hemispheric migrational disorder.

Anatomical substrates that are solely affecting one hemisphere are accompanied by better neurological function and seizure outcome after PIH. Seizure outcome is also noted to be not as good in migrational disorder compared to other aetiologies, either congenital or acquired such as trauma or Rasmussen's chronic encephalitis $[12,20,50$, $51]$.

\section{Electroencephalography}

The electroencephalographic abnormalities on the affected hemisphere are usually multifocal, diffuse and independent, reflecting the extent of the hemispheric involvement and the severe epileptogenicity. Epileptic abnormalities from the good hemisphere are often encountered; from a prognostic view, it is important to value these and determine if they are secondary or independent. Their presence is not a contraindication to PIH, as they may represent dependent or intermediate epileptogenicity, in which cases, the ultimate seizure outcome should be excellent; their presence remains slightly unfavourable $[8,34,52]$. However, the abnormalities on the "good hemisphere" raise concern about an aetiology which could affect the brain bilaterally, questions the nature of the anatomical substrate and the presence of secondary epileptogenesis. It could be a contribution to understand the persistence of seizures after hemispherectomy [20].

\section{Imaging}

Magnetic resonance imaging, with the different sequences, i.e. T1, T2, flair and contrast, is the imaging modality of choice. It demonstrates the global anatomy, allows to determine the degree of atrophy usually present and provides information concerning the status of the white matter, which may show abnormality before atrophy. Furthermore, it provides important information about the integrity of the "normal" hemisphere. It may show specific changes or show the evolution of lesions, confirming the diagnosis of infantile hemiplegia (Fig. 1), Sturge-Weber, migrational disorder (Fig. 2), Rasmussen's encephalitis (Fig. 3). Computed tomography (CT) scan can demonstrate 
Fig. 1 a MRI axial T1, b coronal T2 large left porencephaly - infantile hemiplegia, from in utero vascular occlusion of left MCA
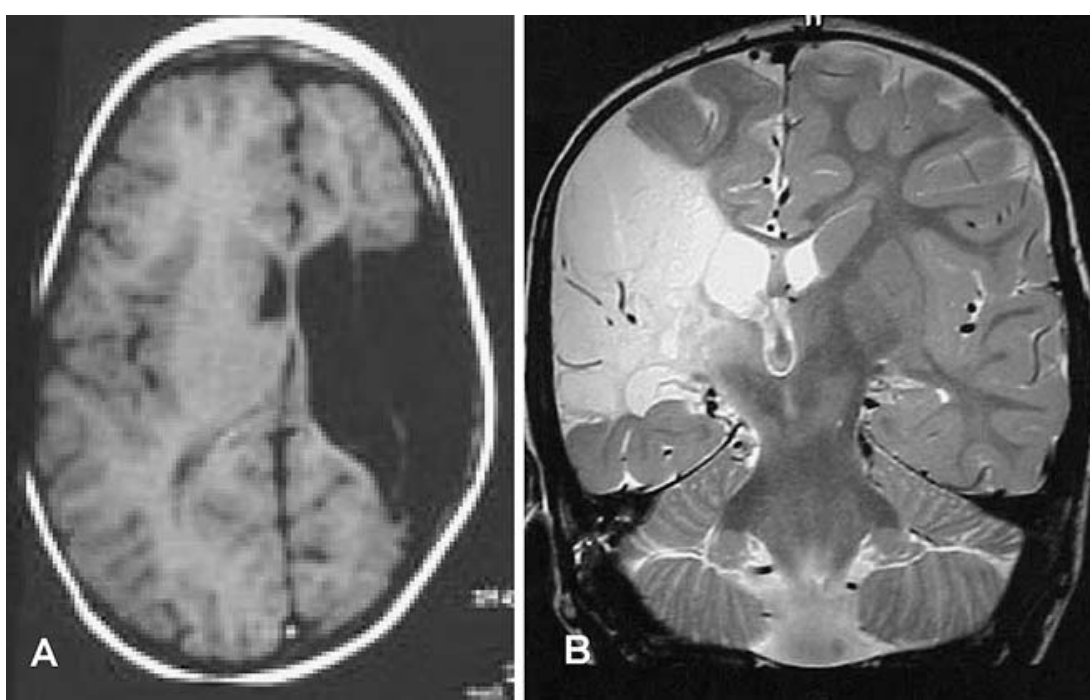

atrophy and some specific diagnostic features but has been replaced by magnetic resonance imaging (MRI). Rarely, an angiogram will add any significant information, and thus, is not part of the routine imaging. The presence of atrophy demonstrated radiologically at the level of the cerebral peduncle and medullary pyramid is also indicative of a severe cortical motor problem which should not be worsened by surgery (Fig. 4). In instances of few MRI abnormalities, functional imaging with positron emission tomography (PET) scan can be contributing in demonstrating extensive abnormal hypometabolic areas [9] (Fig. 5).

The MRI is also useful for the preparation of the surgical strategy. Ventricular size, configuration of the callosum, thickness of the brain, configuration of the insula-basal ganglia complex should be understood before undertaking surgery. Good understanding of the three dimensional individual brain anatomy will make PIH safer.
Neuropsychology

Neuropsychology determines the status of brain functioning before surgery and documents cognitive functions which are usually below average; we have, however, encountered instances of normal IQ [22, 29]. Serial testings before surgery may document a temporal profile of cognitive degradation secondary to progressing brain pathology such as in Rasmussen's encephalitis or the deleterious effects of repeated seizure and the development of an epileptic encephalopathy; regression in development quotient (DQ) is not unusual. In our experience, the demonstration of severe cognitive deficits reflects the involvement of both hemisphere and raises concerns about seizure outcome; persistent seizures have been encountered more frequently in patients with severe mental impairment, operated on the basis of clearly lateralizing electroencephalograms and
Fig. 2 MRI T2, a coronal, b axial enlarged right hemisphere, enlarged ventricle, abnormal gyration, abnormal grey-white matter differentiation, characteristic of hemimegalencephaly
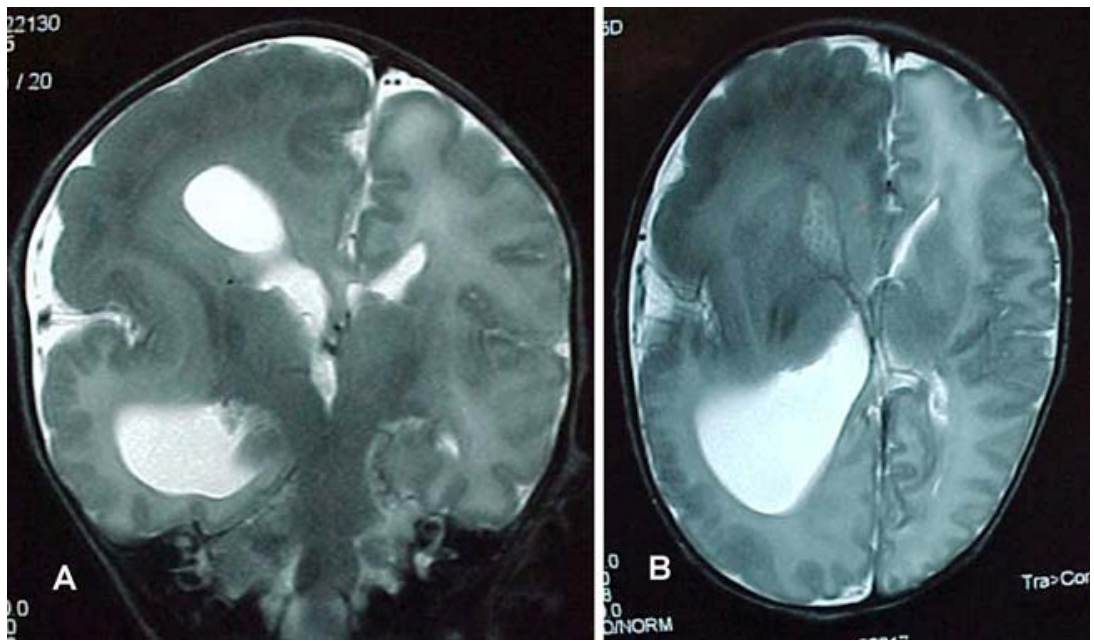
Fig. 3 Rasmussen's chronic encephalitis a MRI, T1, coronal. Mild enlargement of the frontal horn, and smaller right hemisphere, at an early stage of the disease, b CT axial, with contrast. Severe atrophy of the left hemisphere in a late stage
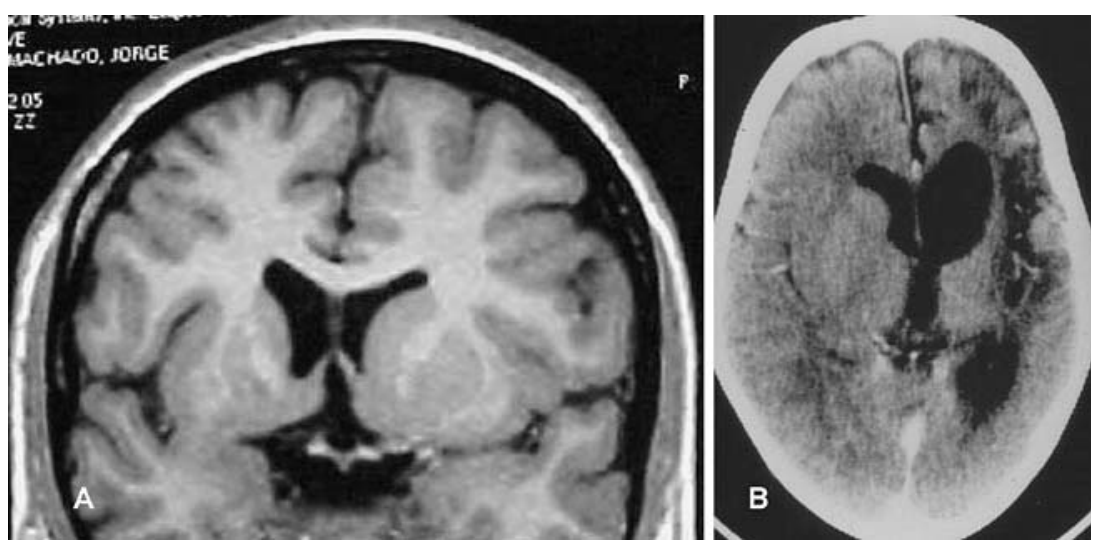

imaging. In these instances, the objective of surgery may shift from curative to palliative but still be very worthwhile [47].

\section{Surgical method of peri-insular hemispherotomy}

Peri-insular hemispherotomy is a surgical method of functional hemispherectomy. It allows to disconnect the hemisphere through a peri-insular approach requiring only removal of the fronto-parieto-temporal opercular cortices (Figs. 6 and 7).

a) skin and bone flap (Fig. 8)

Surgery is carried out under general anaesthesia with the patient supine, a cushion under the ipsilateral shoulder and the head turned contralateral to surgery and kept horizontal; the head is either fixed in a pin clamp or rests on a soft horseshoe headrest and is taped. The skin and craniotomy flaps are planned to allow access around the insula. Taking into account the

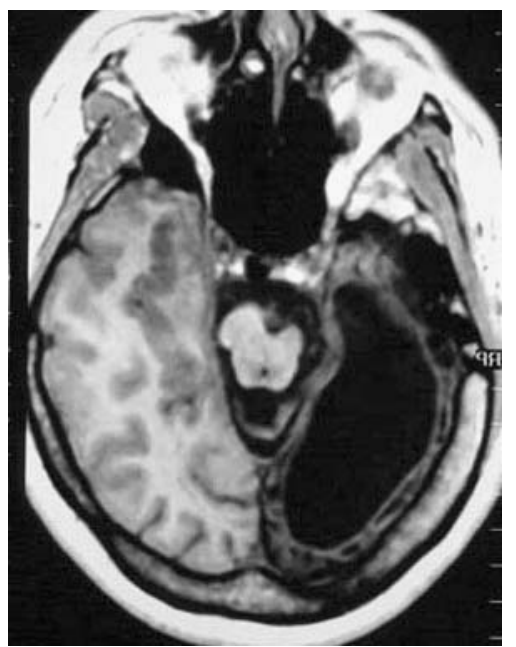

Fig. 4 MRI, T1, axial (temporo-occipital). Severe atrophy of the left hemisphere. Note the severe atrophy of the left cerebral peduncle atrophy and brain shift that may exist, the MRI is useful in appreciating the projected skin and bone flaps. The flaps should extend anteriorly from the level of the coronal suture, go posteriorly $3-4 \mathrm{~cm}$ behind the external auditory canal, allowing them to reach the posterior insula. The flaps do not need to reach the floor of the middle fossa but should reach the midconvexity and be high enough to provide comfortable access to the suprasylvian circular sulcus, and eventually, once in the ventricle, the corpus callosum. Preoperative analysis of the coronal and sagittal MRI helps in defining the exact site and size of the flaps (Fig. 9). The dura is reflected either rostrally or caudally. The brain exposure should provide at least $2-$ to $2.5-\mathrm{cm}$ exposure on either side of the sylvian fissure. This can vary according to the degree of atrophy and whether the intraventricular portion of the operation will be done through an already existing large porencephaly, such as in middle cerebral artery (MCA) prenatal infarct; more exposure is useful in situation where little atrophy is present, such as in early encephalitis or hemimegalencephaly.
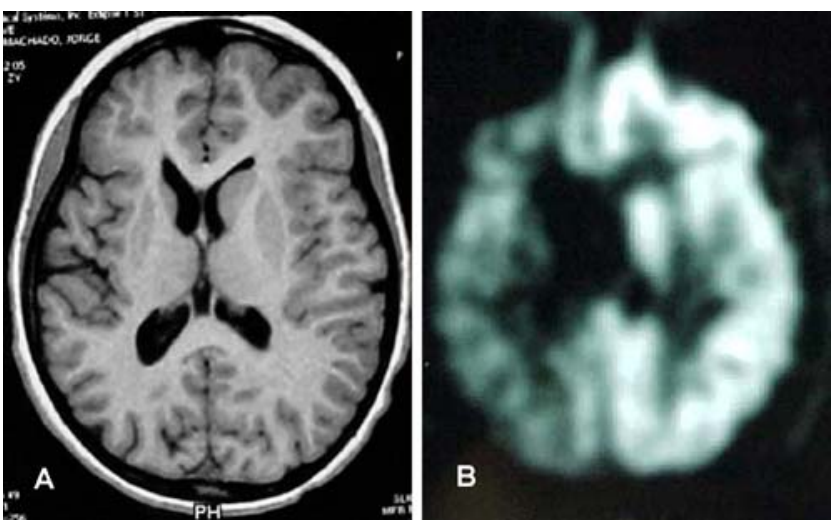

Fig. 5 a MRI, T1, axial. Mild atrophy of the right hemisphere in the early stage of Rasmussen's chronic encephalitis, b FDG-PET in the same patient demonstrating diffuse right hemispheric glucose hypometabolism 

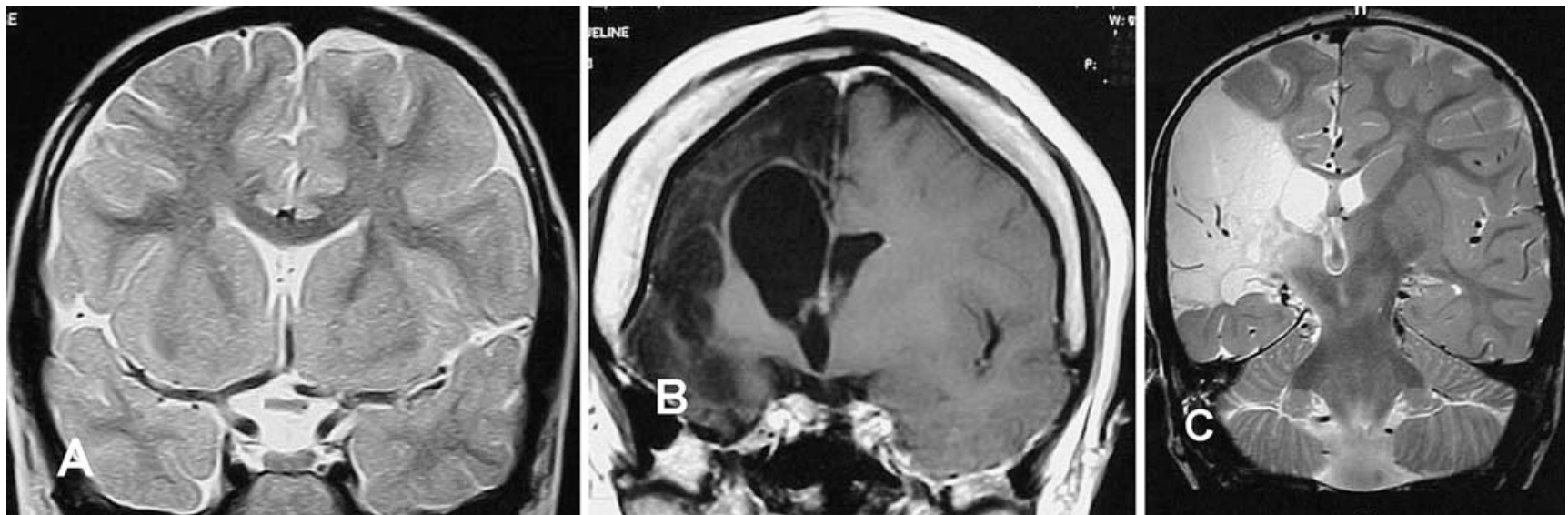

Fig. 6 MRI a coronal T2, observe the normal perisylvian anatomy, and the angle for the callosotomy (almost horizontal to the callosum), b coronal $\mathrm{T} 1$, note the disturbed superficial anatomy and the possibility to do a parasagittal callosotomy directly (vertical to the approach), c coronal T2, note the absence of insula and basal ganglia, which will modify the surgical stages, and exclude the insular stage of $\mathrm{PIH}$ b) PIH has three major surgical stages, i.e. supra-insular window, infra-insular window, insula. Each has technical steps that are now detailed. Magnification with the operating microscope is useful. The illustrations refer to a left PIH.

The supra-insular window stage

The aim of this stage is to transect the corona radiata from the frontal to parietal region and reach the ventricle to access the corpus callosum in its whole extent; this will allow to disconnect the whole of the suprasylvian portion of the hemisphere (Fig. 10).

\section{Resection of the fronto-parietal opercular cortex}

The first step is accomplished by resecting the frontal and parietal opercular cortex using a subpial resection technique with suction and biporal (SB) or ultrasonic aspirator (UA), depending on the tissue consistency (Fig. 11). This needs to be done with preservation of arteries and veins reaching the convexity, which prevents infarct of the disconnected brain. The resection of the fronto-parietal operculum will allow the surgeon to visualize through layers of pia, the insular cortex and the vessels in the sylvian fissure. This exposure is extended rostrally to reach the circular sulcus corresponding to the white matter of the corona radiata just rostral to the insula. Once this has been carried out from the most anterior frontal part to the mid-parietal region, the suprasylvian insular cortex is completely exposed.

\section{Transsection of the corona radiata}

The second step consists in transsecting the corona radiata aiming at opening the lateral ventricle from the frontal horn to the trigone (Fig. 12). Using SB or the UA, the white matter at the level of the circular sulcus is transacted in a plane perpendicular to the insula until the lateral ventricle is reached; thus, this incision is just rostral to the basal ganglia and thalamus. The opening in the ventricle is then extended
Fig. 7 Anatomical preparation. a Coronal section illustrating the three surgical stages of peri-insular hemispherotomy, b lateral view illustrating the resected frontoparieto-temporal opercular cortices, and the sylvian vessels
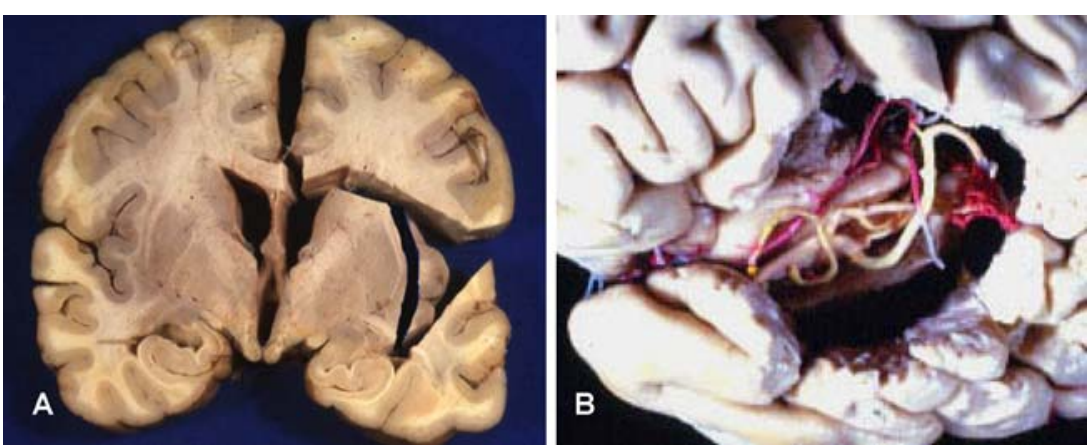
Fig. 8 a Skin incision for PIH bone, b flap for PIH
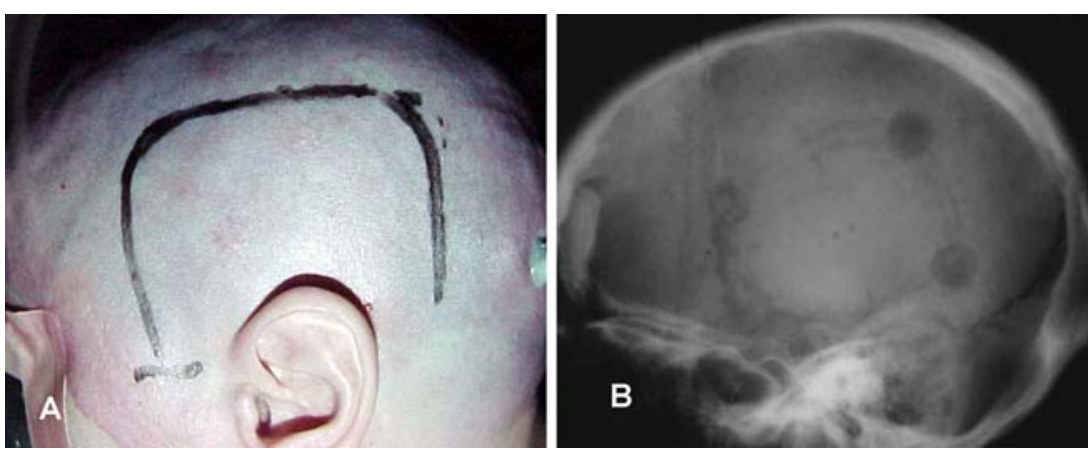

anteriorly and posteriorly. One can, then, rely on the identification of the choroid plexus and visualize the foramen of Monroe for orientation.

\section{Transventricular parasagital callosotomy}

The third step consists in a transventricular parasagittal callosotomy (Fig. 13). A self-retaining retractor applied against the rostral part of the hemispheric opening may be useful to keep the ventricle wide opened. Before callosotomy, we have found it easier to identify the callosum by first proceeding to a rostro-caudal incision on the medial wall of the lateral ventricle, perpendicular to the callosum (Fig. 14). SC is used to go through the ependyma, cingulate gyrus and reach the medial pia; eventually, the falx will be recognized through the pia; the anatomy of the cingulate gyrus running across should be recognized as it is being transected on the way to reach the pericallosal cistern. Identification of the pericallosal vessels is an excellent anatomical landmark with, caudally, the callosum that is recognized by its white colour. A transventricular parasagittal callosotomy can then be carried out consisting of transecting all tissue as it enters the callosum from the medial wall of the ventricle. As the surgical approach is not interhemispheric but performed from the ventricle, the callosal section is slightly oblique and parasagittal (Fig. 13). It must extend anteriorly toward and around the genu to reach the rostrum, and posteriorly, go around the splenium. The callosotomy is done by visualizing the tissue in the pericallosal cistern from within the ventricle; the thin layer of parasagittal tissue is transected with SB, aiming at exposing the parasagittal vessels or the falx, this being the evidence of neural fiber interruption. In doing so, the contralateral cingulum, frontal lobe, anteriorly, falx and medial pia, posteriorly, are visualized. At the level of the genu, as the callosum is thicker, great care is necessary not to pass through the callosum and end up contralaterally; visualizing the pericallosal vessels confirms the exact location and orientation.

\section{Posterior hippocampotomy}

Once around the splenium, extending the medial incision anteriorly to reach the choroidal fissure interrupts the outflow of the hippocampus through the fimbria-fornix (Fig. 15). This posterior hippocampotomy does not allow the removal of the hippocampus, thus, partly de-efferented.

\section{Fronto basal disconnection (Fig. 21)}

The fifth step aims at isolating the frontal lobe from ipsilateral connections by incising just anterior to the basal ganglia in a coronal plane. This is done working from the pterional area toward the parasagittal callosal incision at the rostrum, in a coronal plane from inside the frontal horn, aiming to the edge of the sphenoid wing; the edge of the
Fig. 9 MRI, T1. a Coronal, and b sagittal, useful in planning surgery (ventricular size, orientation of callosum, atrophy of sylvian region, etc.)
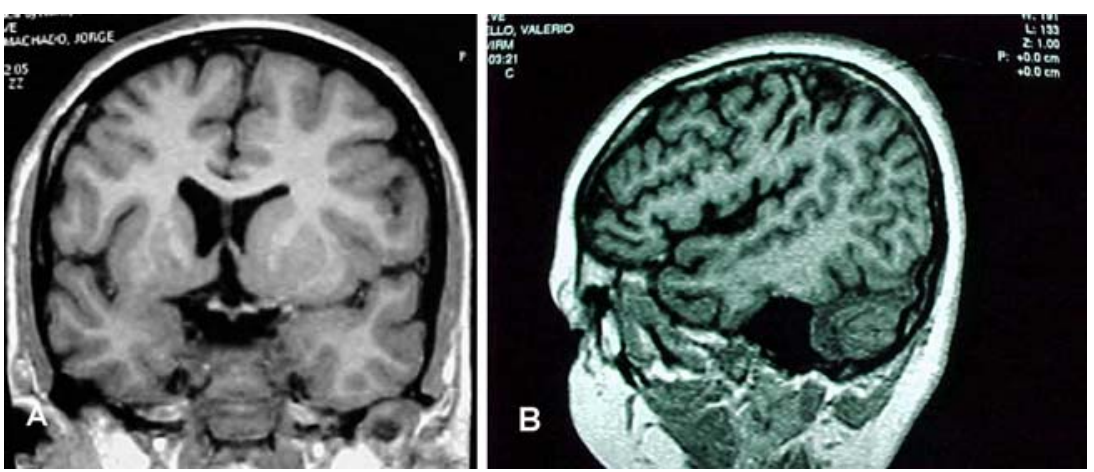


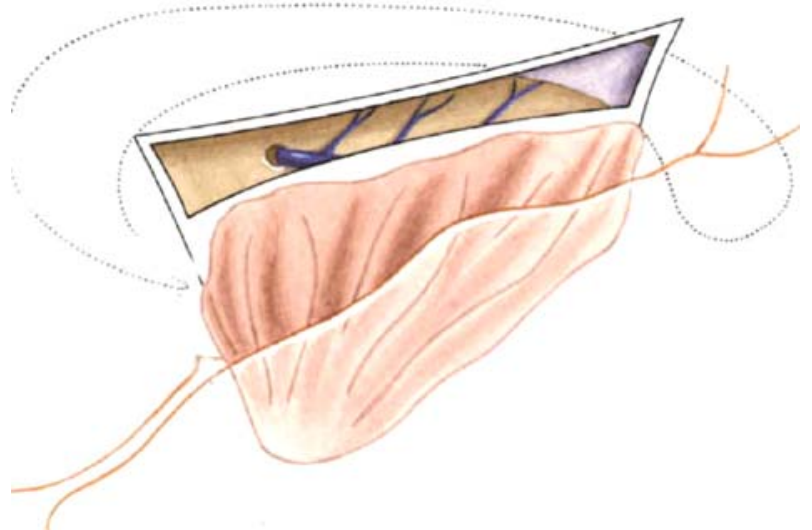

Fig. 10 Suprasylvian window-lateral

sphenoid wing, seen from the pterional area and also transpially, is a good visual landmark for the posterior extent of this frontal incision. The identification of the olfactory tract and gyrus rectus provides good anatomical landmarks when reaching medially. Care is necessary not to damage the optic nerve. Preserving the basal pia adds safety to this step.

The infra-insular window stage

The aim of this stage is to disconnect the whole temporal lobe.

There are four steps to the infra-insular stage. Here, also, major cortical arteries and veins are to be preserved.

\section{Resection of the temporal opercular cortex}

The temporal operculum (T1) is removed in a subpial matter exposing the insular cortex (Fig. 16). The extent of removal is as far back as the posterior insula. At that site, the temporal opercular removal should reach the suprasylvian opercular removal. T1 removal is extended anteriorly and medially to reach the uncus. This is done using CS

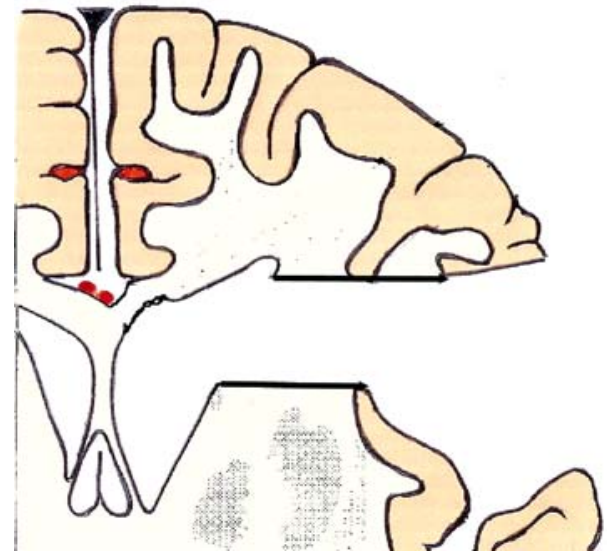

Fig. 12 Suprasylvian — coronal—section of corona radiata

or UA. The insula is, thus, completely exposed which allows access to the circular sulcus caudally.

\section{Transsection of the temporal stem}

At the level of the circular sulcus, the white matter is transsected to reach the temporal horn which is opened from its most anterior aspect to the trigone (Fig. 17). At this moment, the whole lateral ventricle, infra- and suprasylvian are accessible around the insula.

\section{Resection of the amygdala}

The uncus and amygdala are excised by subpial aspiration (Fig. 18). The extent of supero-medial removal of the amygdala does not transgress an imaginary line between the roof of the temporal horn and the medial temporal pial bed. There are no visible anatomical boundaries outlining the supero-medial aspect of the amygdala. The optic tract may be visualized in the cistern if the medial resection is maximal; this is a good anatomical landmark and represents the limit of supero-medial removal of the amygdala. The

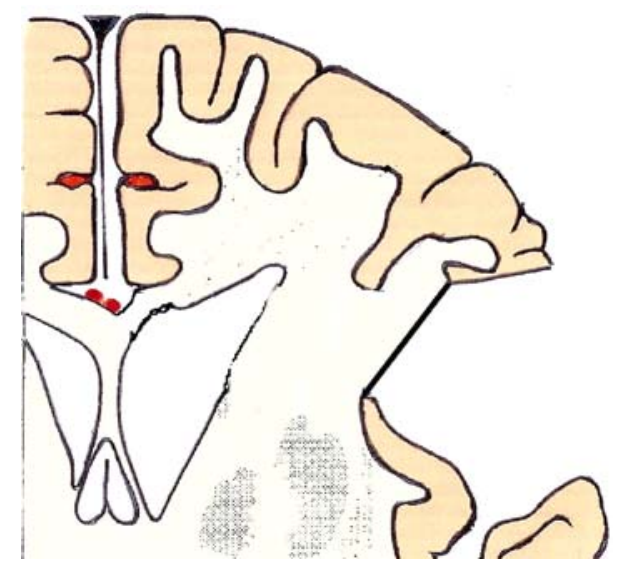

Fig. 11 Suprasylvian—coronal—opercular resection

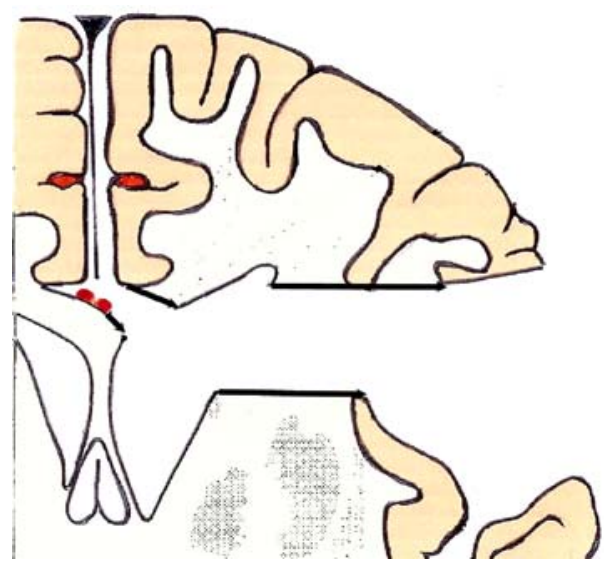

Fig. 13 Suprasylvian - coronal—parasagittal callosotomy 
Fig. 14 a Suprasylvian-lateral-medial vertical incision approaching the corpus callosum, b per-operative microphotograph - transventricular parasagittal callosotomy incision at the level of the genu of the corpus callosum

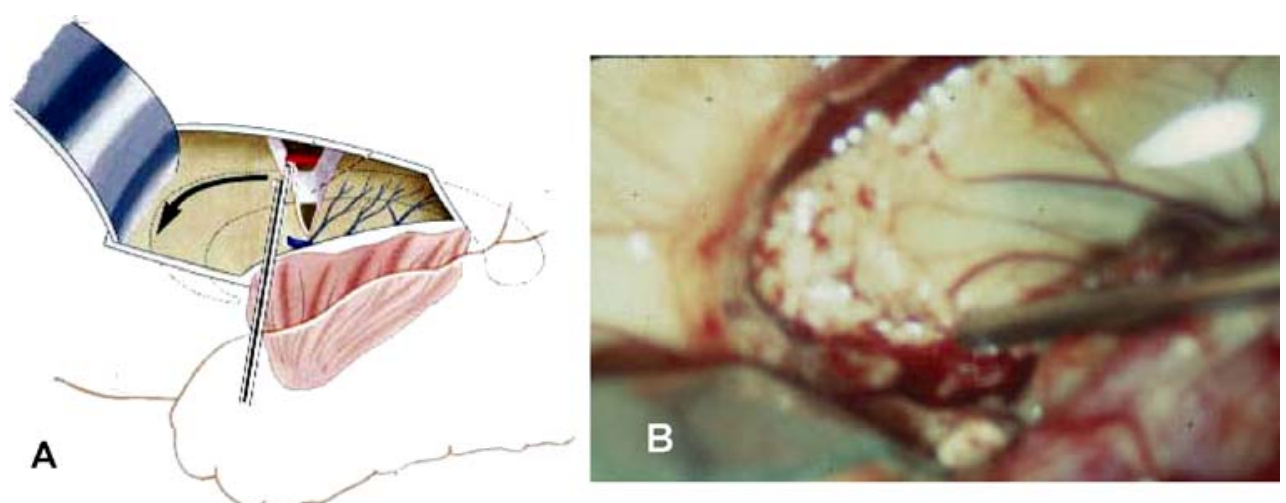

risk of not recognizing this landmark is to end up in a plane rostral to the choroidal fissure, medial to the temporal horn; this is to say in the basal ganglia. We recognize that the clinical consequence may not be the same when this happens in PIH, unlike an anterior temporal lobectomy.

\section{The anterior hippocampus}

As the posterior hippocampotomy has previously been carried out in the supra-insular window stage (step 4), the hippocampus does not need to be completely resected but the disconnection completed; this is ensured by removing the anterior hippocampus until the choroidal fissure is reached; there remains, then, no hippocampal efferents.

The insular stage

The insula is potentially epileptogenic; this stage aims at eliminating its influence [17, 23, 36, 37] (Figs. 19 Figs. 20 Figs. 21). At this point, the insula is the only cortical epileptogenic structure still physiologically connected to the hemisphere. It can either be resected by subpial aspiration or undermined by incising at the level of the claustrum/extreme capsule, working from either side of the

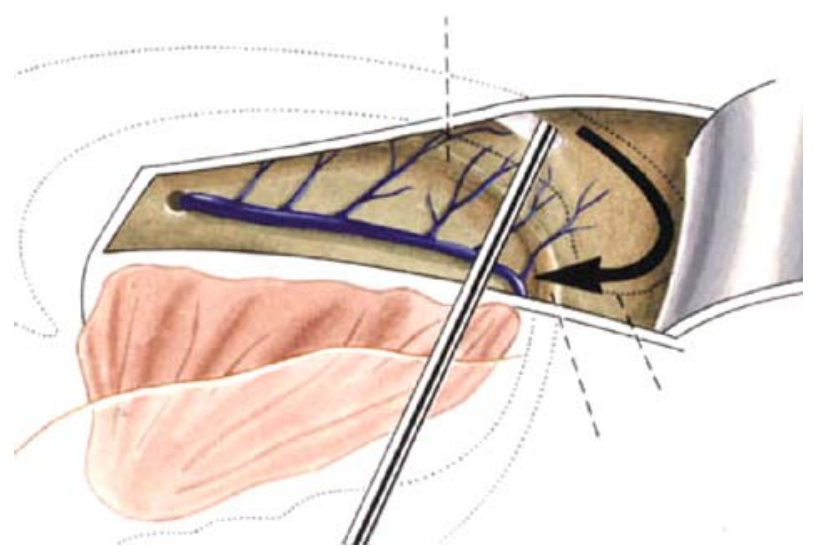

Fig. 15 Suprasylvian — lateral—site of posterior callosotomy, around the splenium, and posterior hippocampotomy insula, i.e. supra- and infrasylvian, at a depth of 5-7 $\mathrm{mm}$. In both techniques, overlying arteries and veins have to be preserved.

Following these three stages, the whole hemisphere is disconnected from ipsilateral and contralateral neurological structures and kept vascularized. Once the disconnection is completed, inspection of the surgical sites is carried out to insure perfect hemostasis. Drains are left in the lateral ventricle and in the subgaleal space. These drains are left to wash out blood debris form the cerebrospinal fluid (CSF) space and to prevent epidural and subgaleal collection. Careful monitoring of the volume of CSF that is drained is mandatory, as overdrainage may be associated with venous haemorrhage occurring topographically at a distance from the surgical site [14].

Bone flap and wound closures are carried out according to standard neurosurgical technique. The drains are removed within $48 \mathrm{~h}$. Antibiotics are not routinely administered, and there are no indications to use corticosteroids.

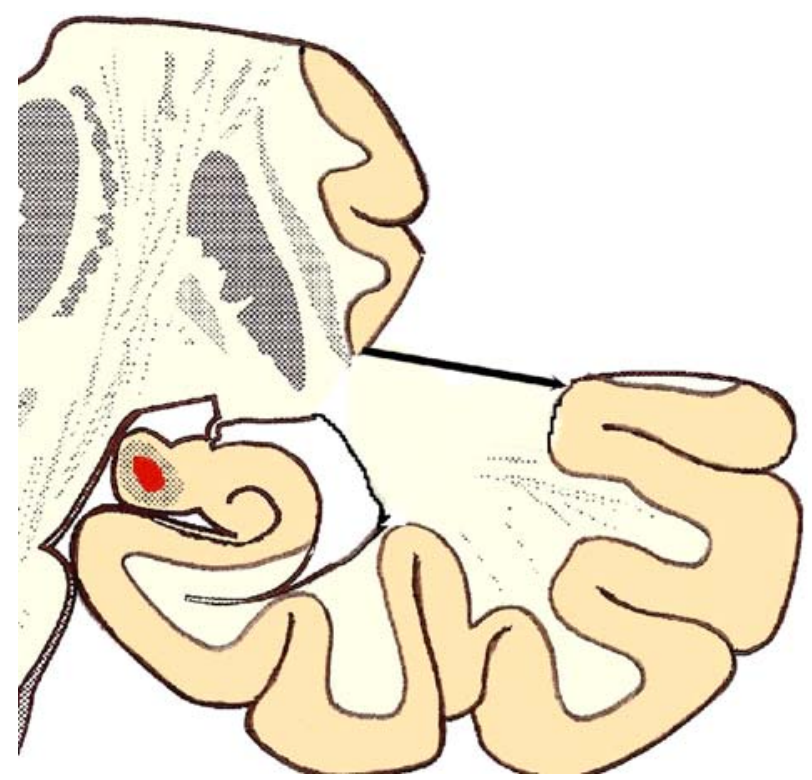

Fig. 16 Infrasylvian - coronal—opercular resection 


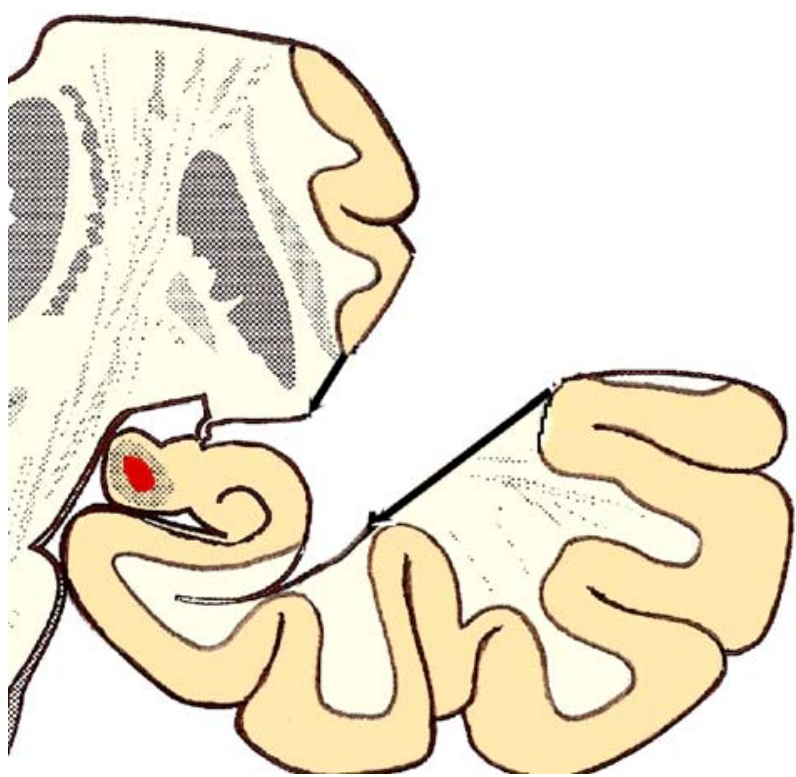

Fig. 17 Infrasylvian - coronal — section of corona radiata (temporal stem)

\section{Complications, technical pitfalls and their avoidance in paediatric peri-insular hemispherotomy}

\section{Preservation of cortical vessels}

In a situation where anatomically, the hemisphere exhibits little, if any, atrophy despite the underlying pathology, great care is necessary to preserve as many arteries and veins as possible [11, 43] (Fig. 22 and Table 3). If this is not done properly, brain swelling and hemispheric infarct secondary to ischemia, from interfering with the arterial supply or venous drainage, may occur, leading to intracranial hypertension, mass effect and death. This may be the case in Rasmussen's encephalitis before severe atrophy, in SturgeWeber, in hemimegalencephaly or non-hypertrophic diffuse hemispheric dysplasia where at the time of surgery, there may be no or little atrophy or the volume of the hemisphere may even be larger than normal. We have encountered one such instance in an early chronic encephalitis adult patient with hardly any atrophy, where many perisylvian arteries

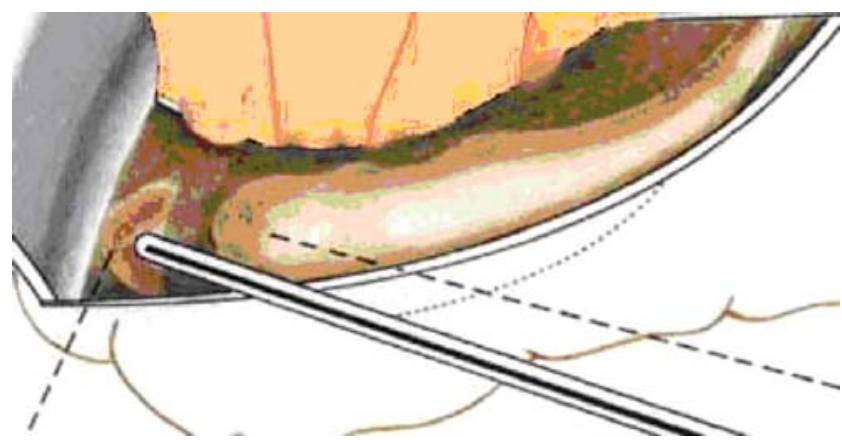

Fig. 18 Infrasylvian - coronal-resection of amygdala and anterior hippocampus and veins were sacrificed; this patient deteriorated rapidly during the third postoperative night and died of transtentorial herniation secondary to hemispheric swelling. The same caution applies for any anatomical substrate with minimal or absent brain atrophy. In instances of severe atrophy, however, such as in large porencephaly secondary to prenatal vascular insult or advanced cases of Ramussen's encephalitis, the issue is not of the same amplitude, as the enlarged ventricle which needs to be widely opened acts as a mechanical buffer in case of any brain swelling. Nevertheless, even in these instances, we make all efforts to preserve as many arteries and veins as possible.

\section{Volume of CSF drainage}

Two of our patients who showed postoperative neurological deterioration were documented to have suffered distant haemorrage from the surgical site. One patient did not wake up from surgery, while the other deteriorated $48 \mathrm{~h}$ after surgery and was found to have remote haemorrhage in the contralateral frontal lobe and in the cerebellum [14]. This child made an uneventful recovery. In this latter instance, the deterioration seems to have coincided with a sudden rapid drainage from the ventricular drain (Fig. 22). We postulate that the sudden drainage of a large volume of ventricular CSF modifies the intracranial dynamic, may create traction on veins and is responsible for the parenchymal haemorrhage as documented radiologically, and subsequently, for the neurological deterioration. This phenomenon can be prevented by setting the ventricular drain at a slightly positive pressure, without vacuum and avoiding sudden drainage of a large amount of CSF.

\section{Hydrocephalus}

One child developed hydrocephalus manifesting at 1 month after surgery. This was successfully treated with a ventriculo-peritoneal CSF shunt. The potential for hydrocephalus is present in any intracranial surgery. The risk for hydrocephalus after peri-insular hemispherotomy is theoretically increased in cases of infection or trauma as both these aetiologies may affect the patency of the subarachnoid space, which can be further altered by surgery. In the single patient who needed a shunt, the aetiology was infantile hemiplegia seizure syndrome associated with neurofibromatosis without specific features favouring hydrocephalus.

PIH before maximal deficits

In children who did not have maximal hemispheric deficit before surgery, their motor or visual field status postoperatively were, as expected, definitively aggravated. Most of these patients suffered from progressive Rasmussen's 
Fig. 19 Anatomical preparation illustrating the incision undermining the insula (a) anatomical preparation-axial, (b) MRI axial $\mathrm{T} 1$
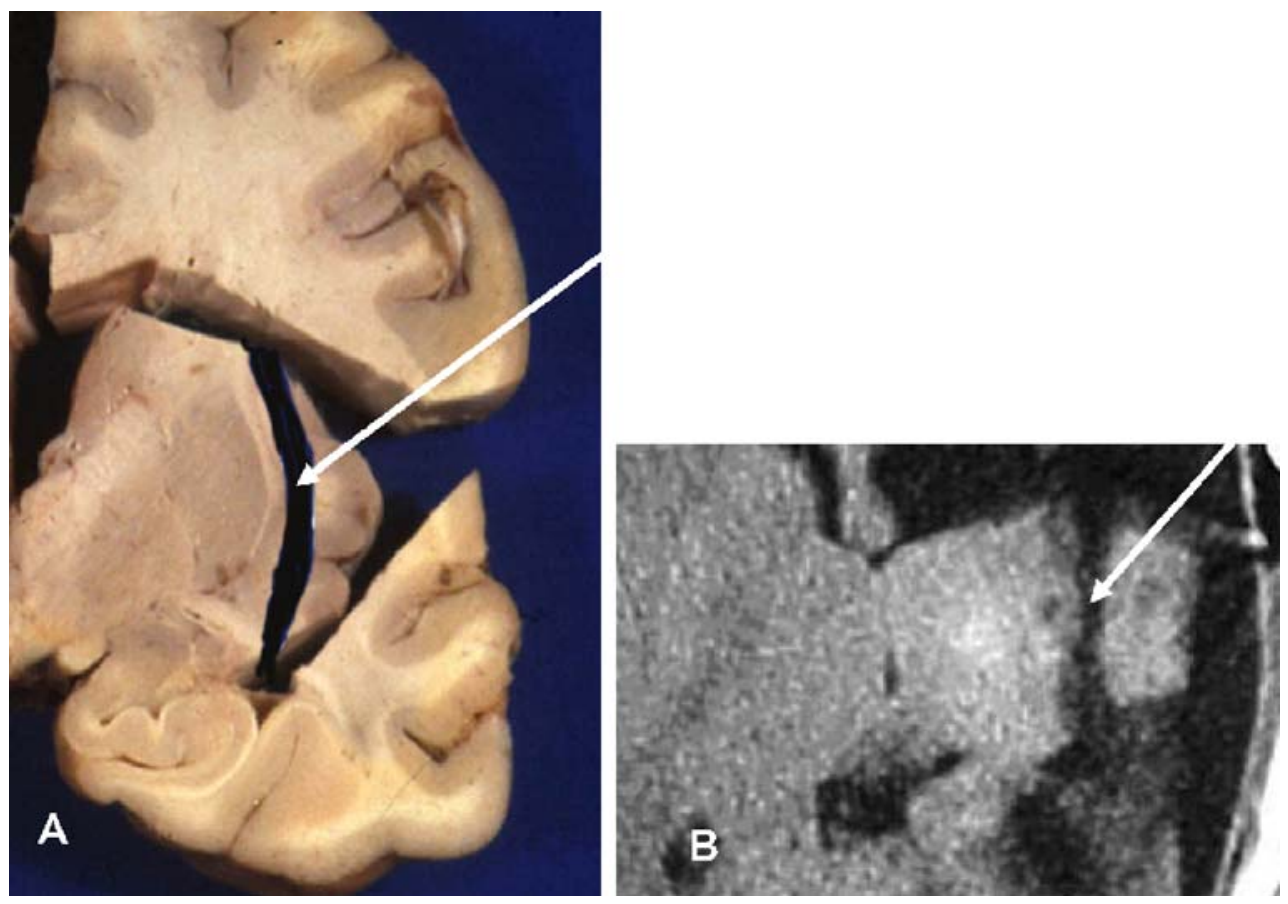

chronic encephalitis, and surgery was carried out based on the severity of the seizures, knowing that the natural history of the disease would lead to maximal deficit anyway. Postoperatively, the recovery manifested by the return of tone and some gross motor function within 1 month. No patient demonstrated any discomfort or changes in habits from the aggravation of their visual field.

\section{Seizure outcome}

Seizure outcome is expressed according to Engel's classification and based on a follow-up of 9 years. Of 37 children with adequate follow-up, 34 have remained in Engel's Class I since surgery (90\%), while three are in class II. In five children, we do not have adequate follow-up to categorize their seizure outcome. Overall, all children have been helped by surgery. This figure can be broken down according to aetiologies, which do influence the success rate of surgery. The best results have been obtained in children suffering from infantile hemiplegia (93\%), secondary to prenatal vascular occlusion of the carotid but most often middle cerebral artery territory. Surgical outcome after PIH in Rasmussen's encephalitis which also, in most instances, is strictly a unilateral condition but acquired, is excellent (90\%). Results obtained in unilateral hemispheric involvement where the anatomical substrate is one of hypertrophic or non-hypertrophic migrational disorders are not as good $(80 \%)$, likely reflecting a different physiopathology of epileptogenicity; one could suspect the presence of migrational abnormalities in the preserved hemisphere or the early development of an epileptic encephalopathy, already in utero (Table 4) [50].
Fig. 20 Postoperative MRI T1. a sagittal, illustrating the perisylvian incision, b sagittal, illustrating the parasagittal callosotomy and vertical median incision
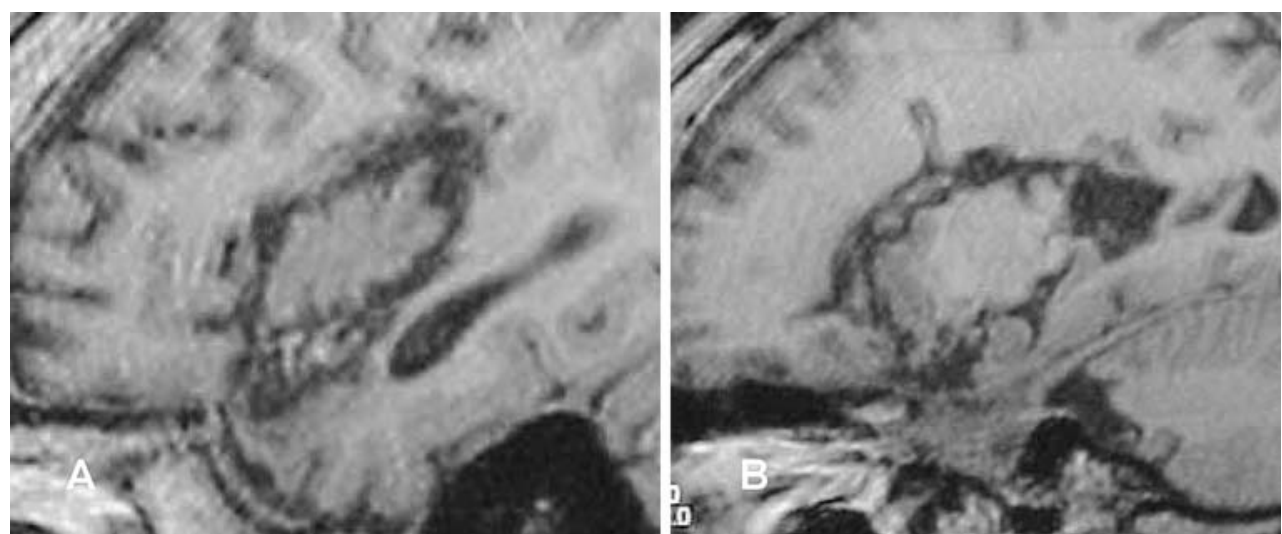


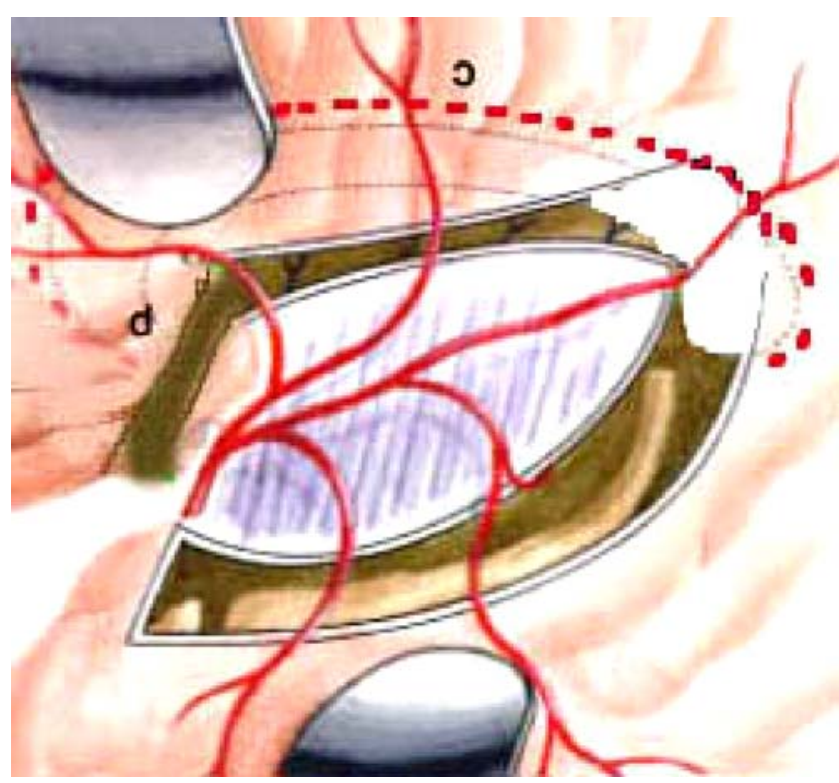

Fig. 21 Lateral view illustrating the peri-insular incision and preservation of cortical vessels

\section{Discussion}

All the techniques of hemispherectomy that have been developed to replace anatomical hemispherectomy had a common denominator which was to reduce the volume of the residual postoperative cavity, in view of eliminating the appearance of superficial cerebral hemosiderosis. This complication has not been reported after hemispherectomy over the last 30 years. However, the techniques have been modified in view of reducing the complication rate while achieving the same seizure control.

Peri-insular hemispherotomy represents the latest modification of functional hemispherectomy. It follows the same surgical principle of "anatomical subtotal removal of the hemisphere and complete disconnection". In PIH, the ratio disconnection to excision is largest. As opposed to a

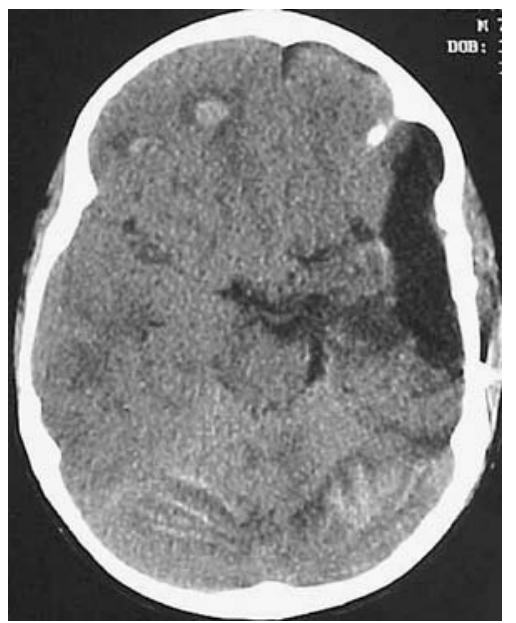

Fig. 22 CT, axial, demonstrating haemorrhagic lesion in the right frontal lobe (contralateral to surgery) and blood over the cerebellum
Table 3 Complications in peri-insular hemispherotomy $(\mathrm{Nb}: 43)$

resective strategy consisting in anatomical hemispherectomy, hemidecortication or modified hemispherectomy, PIH is classified under disconnective strategy of hemispherectomy (Fig. 23). It resulted from the demonstration that the hemisphere could be disconnected, made nonfunctional, through very small removal of brain tissue $[24,25,44,46]$. The complications-benefits ratio have been clearly documented and confirm that this surgical methodology of hemispherectomy provides excellent seizure outcome, with a low incidence of side effects or complications. The epilepsy outcome should be identical to any other method of hemispherectomy, as physiologically, PIH eliminates the influence of the whole hemisphere; the outcome is not, then, only technique dependent but results, in a great part, from the anatomical substrate responsible for the epilepsy [20]. The nature and rate of complications of some other methods of hemispherectomy are available in the literature $[1,2,6,7,13,16,41,42,45,48,56]$. When comparing the rate and nature of complications, PIH provides a very low incidence of complications. Some of the potential complications of PIH have been avoided by understanding their causes and modifying the technique; this is the case in proposing, to spare cortical vessels in view of preventing brain swelling. Complications not specific to $\mathrm{PIH}$, such as overdrainage of CSF, should now be avoided by close monitoring. The rate of hydrocephalus after PIH is the lowest encountered in such a large series. Specifically, we have not encountered any hydrocephalus after PIH in diffuse migrational disorders, compared to other techniques. We believe that the minimal interference with the subarachnoid space remains the logic explanation for this low rate of postoperative hydrocephalus, as compared to other techniques of hemispherectomy that requires removal of half the subarachnoid space. By comparison with techniques of anatomical hemispherectomy or hemidecortication, in which the extent of surgery requires large exposure of almost the whole hemisphere, with a large skin and bone flaps, the exposure in PIH is relatively small which contributes to less blood loss, electrolytes and coagulation disturbance and favours a shorter operative time; in children, these influence the operative and perioperative course and management [6].

Cognitive performance are, in most patients, below average before surgery and often show regression secondary to frequency of seizures. General brain disturbance may result from frequent seizures, but focal interference of seizures can also be deleterious, particularly, toward language development $[5,33,35]$. It is surprising to find 
Table 4 Complications and seizure outcome following PIH according to etiology

\begin{tabular}{|c|c|c|c|c|c|c|c|}
\hline \multirow[b]{2}{*}{ Aetiology } & \multirow[b]{2}{*}{$\mathrm{Nb}$ evaluable/total nb } & \multicolumn{5}{|c|}{ Engel's Class } & \multirow[b]{2}{*}{ Complications } \\
\hline & & I & II & III & IV & Death & \\
\hline IHSS & $15 / 17$ & 14 & 2 & 0 & 0 & 1 & Remote bleed (2) \\
\hline \multicolumn{8}{|c|}{ Hydrocephalus (1) } \\
\hline $\mathrm{CE}$ & $12 / 13$ & 11 & 1 & 0 & 0 & 0 & \\
\hline HM & $2 / 3$ & 2 & 0 & 0 & 0 & 0 & \\
\hline Migration & $3 / 4$ & 2 & 1 & 0 & 0 & 0 & \\
\hline Others & $5 / 6$ & 5 & 0 & 0 & 0 & 0 & \\
\hline
\end{tabular}

that despite complete seizure control, the postoperative evolution of the developmental quotient does not follow a standard positive pattern $[22,29]$. Without there being clear explanations, it appears that some patients will show more improvement in cognitive functions than others. Even if improvement does not occur, deterioration is usually stopped, and once seizures are controlled, the brain is in the optimal condition to manifest its whole psychosocial development potential.

Patients with anatomical hemispheric dysfunction and frequent seizures often creating bilateral hemispheric dysfunction harbour abnormal behaviour. As in many instances, the hyperactive and aggressive behaviour improves rapidly after cessation of seizure, we can conclude that behaviour disturbances are secondary to bilateral brain disturbances resulting from seizures [21, 22].

The interval between seizure onset and control of seizure may be an important variable. Though instinctively, one would suspect a better outcome with an early treatment, it is, however, difficult to confirm that. The development of secondary epileptogenesis and epileptic encephalopathy may be related to age at onset of seizure and interval before treatment. We have not been able to demonstrate that this phenomenon exists, except in Rasmussen's chronic encephalitis (adult and paediatric series), where there appears to be a linear relation between seizure outcomes and interval; a shorter interval between seizure onset and surgery is associated with a better seizure outcome [51]. The development of an epileptic encephalopathy can result from high seizure frequency and time interval between seizure onset and surgery.

It appears that the earliest PIH is carried out, the maximum will the benefit be. Benefits manifest through seizure control and should provide the best environment for the optimal psychosocial development of the child. There remains a subcategory of potential candidates for PIH where surgery may not be carried out right away, but delayed, due to the absence of maximal deficit and possible benefits from other medical therapy. In Rasmussen's encephalitis, a European consensus has defined some

Fig. 23 Disconnective hemispherectomy

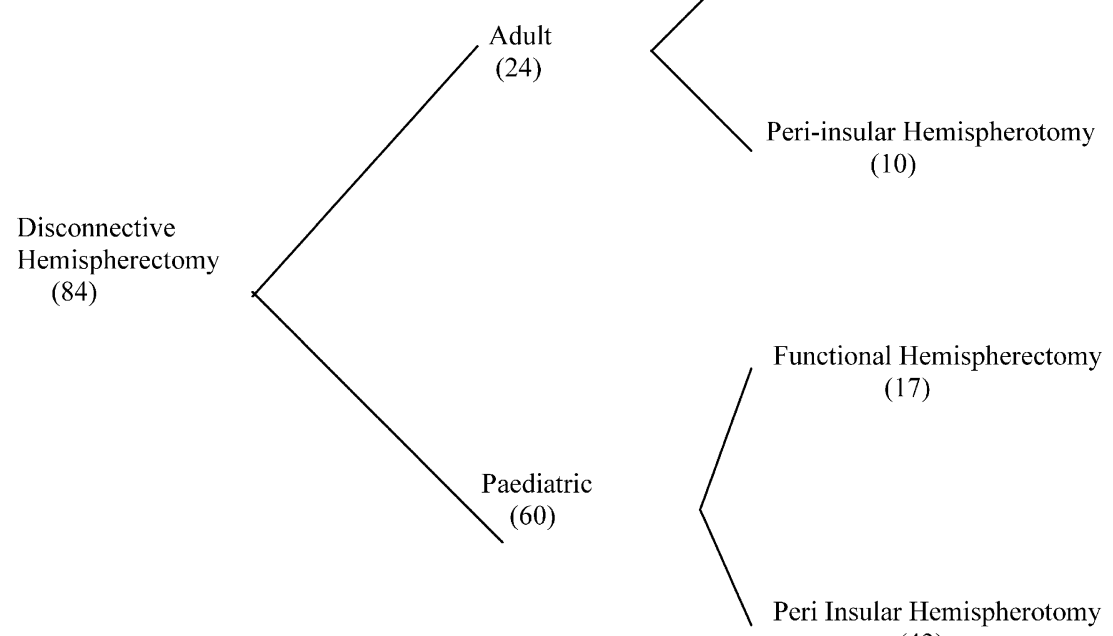

(43)

Author's experience with disconnective hemispherectomv for epilensv 
guidelines for the management of these patients, with the use of immunotherapy before surgery in certain patients [4]. In most instances, however, PIH should be performed as soon as the situation for such surgery is met and brought to the attention of the epilepsy surgeon.

Among the different surgical methods of hemispherectomy, peri-insular hemispherotomy appears to provide the lowest complication rate. Critical patient selection, clear three-dimensional understanding of the patients' brain anatomy and constant perioperative anticipation are keys to successful surgery.

\section{References}

1. Adams CBT (1983) Hemispherectomy: a modification. J Neurol Neurosurg Psychiatry 46:617-619

2. Beardsworth ED, Adams CBT (1988) Modified hemispherectomy for epilepsy: early results in 10 cases. Br J Neurosurg 2:73-84

3. Bernasconi A, Bernasconi N, Lassonde M, Toussaint PJ, Meyer E, Reutens DC, Gotman J, Andermann F, Villemure JG (2000) Sensorimotor organization in patients who have undergone hemispherectomy: a study with (15)O-water PET and somatosensory evoked potentials. Neuroreport 11(14):3085-3090

4. Bien CG, Granata T, Antozzi C, Cross JH, Dulac O, Kurthen M, Lassmann H, Mantegazza R, Villemure JG, Spreafico R, Elger CE (2005) Pathogenesis, diagnosis and treatment of Rasmussen encephalitis: a European consensus statement. Brain 128:454-471

5. Boatman D, Freeman J, Vining E, Pulsifer M et al (1999) Language recovery after left hemispherectomy in children with late-onset seizures. Ann Neurol 46:579-586

6. Brian JE, Deshpande JK, McPherson RW (1990) Management of cerebral hemsipherectomy in children. J Clin Anesth 2:91-95

7. Cabiese F, Jeni R, Landa R (1957) Fatal brain stem shift following hemispherectomy. J Neurosurg 14:74-91

8. Carmant L, Kramer U, Riviello JJ, Helmers SL, Mikati MA, Madsen JR, Black PM, Lombroso CT, Holmes GL (1995) EEG prior to hemispherectomy: correlation with outcome and pathology. Electroencephalogr Clin Neurophysiol 94:265-270

9. Caplan R, Chugani HT, Messa C, Guthrie D, Sigman M, de Traversay J, Mundy P (1993) Hemispherectomy for intractable seizures: presurgical cerebral glucose metabolism and postsurgical non-verbal communication. Dev Med Child Neurol 35:582-592

10. Dandy W (1928) Removal of right cerebral hemisphere for certain tumors with hemiplegia. JAMA 90:823-825

11. Daniel RT, Villemure JG (2003) Peri-insular hemispherotomy: potential pitfalls and complication avoidance. Stereotact Funct Neurosurg 80:22-27

12. Daniel RT, Broggi G, Farmer JP, Montes JL, Villemure JG (2003) Indicators of seizure outcome following hemispherectomy. Eur J Neurol 10(suppl 1):21

13. Davies KG, Maxwell RE, French LA (1993) Hemispherectomy for intractable seizures: long-term results in 17 patients followed for up to 38 years. J Neurosurg 78:733-740

14. De Ribaupierre S, Villemure JG, Chalaron M, Cotting J, Pollo C (2004) Contralateral frontal and cerebellar haemorrhages after peri-insular hemispherotomy. Acta Neurochir 146:743-744

15. Engel J, Cascino GD, Shields WD (1997) Surgically remediable syndromes. In: Engel J, Pedley TA (eds) Epilepsy: a comprehensive textbook. Lippincott-Raven, Philadelphia-New York, pp $1687-1696$
16. Falconer MA, Wilson PJE (1969) Complications related to delayed hemorrhage after hemispherectomy. J Neurosurg 30:413-426

17. Freeman JM, Arroyo S, Vining EP, Breiter SN, Barker PB, Pardo CA, Carson BS, Zuckerberg AL (1994) Insular seizures: a study in Sutton's law. Epilepsia 35(suppl 8):49

18. Graveline C, Mikulis D, Crawley AP, Hwang P (1998) Regionalized sensorimotor plasticity after hemispherectomy fMRI evaluation. Pediatr Neurol 19:337-342

19. Griffith HB (1967) Cerebral hemispherectomy for infantile hemiplegia in the light of late results. Ann R Coll Surg Engl 41:183-201

20. Holthausen H, May TW, Adams CBT, Andermann F, Comair Y, Delalande O, Duchowny M, freeman JM, Hoffman H, May P, Oppel F, Oxbury JM, Peacock WJ, Polkey C, Resnick T, Schramm J, Shewmon DA, Tuxhorn I, Vigevano F, Villemure JG, Wyllie E, Zaiwalla Z (1997) Seizures post-hemispherectomy. In: Tuxhorn I, Holthausen H, Boenigk H (eds) Paediatric epilepsy syndrome and their surgical treatment. John Libbey, London, pp 749-773

21. Krynauw RA (1950) Infantile hemiplegia treated by removing one cerebral hemisphere. J Neurol Neurosurg Psychiatry 13:243-267

22. Lindsay J, Ounsted C, Richards P (1987) Hemispherectomy for childhood epilepsy: a 36 years study. Dev Med Child Neurol 29:592-600

23. Mascot C, Villemure JG, Andermann F, Rasmussen T (1990) Hemispherectomy and the insula. Can J Neurol Sci 17:236

24. Mascott C, Choi W, Rasmussen T, Villemure JG (1992) The evolution of functional hemispherectomy at the MNI. Epilepsia 33 (suppl 3):9

25. Mascot CR, Villemure JG (1993) Neuroanatomical principles of peri-insular hemispherotomy: a novel variant of functional hemispherectomy for epilepsy. Epilepsia 34:101-102

26. McKenzie KG (1938) The present status of a patient who had the right cerebral hemisphere removed. JAMA 111:168

27. Oppenheimer DR, Griffith HB (1966) Persistent intracranial bleeding as a complication of hemispherectomy. J Neurol Neurosurg Psychiatry 9:229-240

28. Poirier P, Lassonde M, Villemure JG, Geoffroy G, Lepore F (1994) Sound localization in hemispherectomized patients. Neuropsychologia 32:541-553

29. Pulsifer MB, Brandt J, Salorio CF, Vining EP, Carson BS, Freeman JM (2004) The cognitive outcome of hemispherectomy in 71 children. Epilepsia 45:243-245

30. Ransohoff J, Hess W, in discussion Rasmussen T (1973) Postoperative superficial hemosiderosis of the brain, its diagnosis, treatment and prevention. Ann Neuro Assoc 98:133-137

31. Rasmussen T (1983) Hemispherectomy for seizures revisited. Can J Neurol Sci 10:71-78

32. Rasmussen T, Villemure JG (1989) Cerebral hemispherectomy for seizures with hemiplegia. Clev Clin J Med 56(suppl 1):62-83

33. Rosenblatt B, Vernet O, Montes JL, Andermann F, Schwartz S, Taylor LB, Villemure JG, Farmer JP (1998) Continuous unilateral epileptiform discharge and language delay: effect of functional hemispherectomy on language acquisition. Epilepsia 39:787-792

34. Smith SJM, Andennann F, Villemure JG, Rasmussen T, Quesney LF (1991) Functional hemispherectomy: EEG findings, spiking from isolated brain postoperatively, and prediction of outcome. Neurology 41:1790-1794

35. Vargha-Khadem F, Mishkin M (1997) Speech and langage outcome after hemispherectomy in childhood. In: Tuxhorn I, Holthausen H, Boenigk H (eds) Paediatric epilepsy syndromes and their surgical treatment. John Libbey, London, pp 774-784

36. Villemure JG, Mascott C, Andermann F, Rasmussen TB (1989) Is removal of the insular cortex in hemispherectomy necessary? Epilepsia 30:728 
37. Villemure JG, Mascott C, Andermann F, Rasmussen T (1989) Hemispherectomy and the insula. Epilepsia 34:639-650

38. Villemure JG, Rasmussen T (1990) Functional hemispherectomy: methodology. J Epilepsy 3:177-182

39. Villemure JG, Andermann F, Rasmussen TB (1991) Hemispherectomy for the treatment of epilepsy due to chronic encephalitis. In: Andermann F (ed) Chronic encephalitis and epilepsy: Rasmussen's syndrome. Butterworth-Heinemann, Boston, pp 235-244

40. Villemure JG (1992) Hemispherectomy. In: Resor SR, Kutt H (eds) The medical treatment of epilepsy. Marcel Dekker, New York, pp 243-249

41. Villemure JG (1992) Hemispherectomy techniques. In: Luders HO (ed.) Epilepsy surgery. Raven, New York, pp 569-578

42. Villemure JG (1992) Anatomical to functional hemispherectomy from Krynauw to Rasmussen. Epilepsy Res (Suppl. 5):209-215

43. Villemure JG (1993) Hemispherectomy: techniques and complications. In: Wyllie E (ed) The treatment of epilepsy: principles and practice. Lea and Febiger, Philadelphia, pp 1116-1119

44. Villemure JG, Mascott C (1993) Hemispherotomy: the peri-insular approach: technical aspects. Epilepsia 34(suppl 6):48

45. Villemure JG, Adams CBT, Hoffman HJ, Peacock WJ (1993) Hemispherectomy. In: Engel J (ed.) Surgical treatment of the epilepsies. Raven, New York, pp 511-518

46. Villemure JG, Mascott R (1995) Peri-insular hemispherectomy: surgical principles and anatomy. Neurosurgery 37:975-981

47. Villemure JG (1997) Hemispherectomy: a critical review. In: Ed Tuxhorn I, Holthausen H, Boenigk H (eds) Paediatric epilepsy syndrome and their surgical treatment. John Libbey, London, pp 729-738

48. Villemure JG, Vernet O, Delalande O (2000) Hemispheric disconnection: callosotomy and hemispherotomy. In: Cohadon F,
Dolenc VV, Lobo Antunes J, Pickard JD, Reulen HJ, Sindou M, Strong AJ, Tribolet N, Tulleken CAF, Vapalahti M (eds) Advances and technical standards in neurosurgery. Springer, Berlin Heidelberg New York, pp 25-78

49. Villemure JG (2001) Functional hemispherectomy: evolution of technique and results in 65 cases. In: Luders HO, Comair YG (eds) Epilepsy surgery. Lippincott Williams and Wilkins, Philadelphia-New York, pp 733-739

50. Villemure JG, Meagher-Villemure K, Montes JL, Farmer JP, Broggi G (2003) Disconnective hemispherectomy for hemispheric dysplasia. Epileptic Disord 5(suppl 2):125-130

51. Villemure JG, Daniel RT, Farmer JP, Montes JL, Broggi G, Meagher-Villemure K (2004) Hemispherectomy (in chronic encephalitis). Epilepsia 45(suppl 3):19-20

52. Wennberg R, Quesney LF, Villemure JG (1998) ECoG findings in hemispherectomy. Electroencephalogr Clin Neurophysiol Suppl 48:132-139

53. Wessinger CM, Fendrich R, Ptito A, Villemure J-G, Gazzaniga MS (1996) Residual vision with awareness in the field contralateral to a parietal or complete functional hemispherectomy. Neuropsychologia 34:1129-1137

54. Wilson PJE (1970) Cerebral hemispherectomy for infantile hemiplegia. Brain 93:147-180

55. Wieser GH, Henke K, Zumsteg D, Taub E, Yonekawa Y, Buck A (1999) Activation of the left motor cortex during left leg movements after right central resection. J Neurol Neurosurg Psychiatry 67:487-491

56. Winston KR, Welch K, Adler JR, Erba G (1992) Cerebral hemicorticectomy for epilepsy. J Neurosurg 77:889-895

57. Zattore RJ, Ptito A, Villemure JG (1995) Preserved auditory spatial localization following cerebral hemispherectomy. Brain 118:879-889 